\title{
Research on Big Data and the Innovation of Enterprise Marketing
}

\author{
Yifan Wu \\ School of Information, Capital University of Economics and Business, Beijing 100070, China. \\ wyfbat@sina.com
}

\begin{abstract}
As the products of the development of information era, big data could offer very rich and valuable information for society and enterprises. Marketing is considered as one of the most important part of enterprises, which plays a very significant role in both of society and enterprises. From the present development, more and more cases has proved that combination of marketing and big data would blaze a new ground for the development of society and enterprises. This paper mainly demonstrated the combination inevitability of the both as well as the problems and improvement suggestions for it by methods of literature review and case analysis.
\end{abstract}

Keywords: Big data, Marketing, Innovation.

\section{Backgrounds}

Nowadays, the big data period has come into people's life, and it also became the research hotspot of scientific world. The emerging of big data has changed people's life largely. Variety of data were accumulated by the internet, which means tremendous value if it were analyzed and applied in the marketing industry. It could be found that big data has change the behavior of consumers, the means of media transmission, and the management mode of enterprises. Therefore, marketing need reform itself by following the development tend of big data to help the company reduce cost, market accurately and increase revenue. This article discusses and estimates the application of big data in marketing through the marketing cases study of Alibaba and the theory analysis, and puts forward related measures and suggestions according to the present situation and problems of big data's application so as to promote enterprises for better marketing in use of big data and create greater value.

\section{Literature Review}

\subsection{The Nature of Big Data}

From the surface, big data means vast and various data, which according to the definition of McKinsey Global Institute stated, it is a large-scale data set that has exceeded the traditional database software tool in capacity of getting, storing, managing and analyzing data. To be simple, it is a huge data set that traditional data could not achieve in data capturing, managing and handling in required timeframe.

In the era of data's explosive growth, people often focused their attention on the data itself and ignored the increasingly clear truth behind it that big data was blending the mirror-image lifestyle into people's daily life.

David Gelernter has once illustrated in his works: "the terminal pattern of the internet is 'mirrorimage world" [1]. Mirror-image world means the physical reflection of the real world. Mirror-image existence is considered as an existence mode that represents the relationship between things by data on the basis of computer networks and hardware. Taking the online class as an example, essentially it has no difference with traditional class that the teacher teaches and the students learn except the terminals and networks have replaced the traditional spatialized classroom, as with the online reading, internet shopping and so on. Big data firstly makes the mirror world more detailed which presented the information people used in traditional ways more integrated. Secondly, it makes the motion traditionally based on entity realized on the internet; in other words, it is also called "mirror practice" when the motion achieves in the computer networks that is supposed to realize in real world. [2] 
The characteristics of big data discussed below looks like the coordinate axis; huge quantity of data increases the mirror world more details, large types of data makes it more real, and the fast flowability of data help it more time-efficient.

\subsection{Characteristics of Big Data}

\subsubsection{Large Total Quantum of Data}

Nowadays, with the development of internet, the growth rate of various kinds of data generated doubled generally every day on the internet every two years, taking the famous social platform WeChat as an example, according to the data of 2017, there are over 0.9 billion users on average log in WeChat per day, more than 30 billion massages sent daily, exceeding 600 billion of voice massages, as well as over 70 million times of video transmitted per day, which is clear that the traditional data cannot be comparable to big data in total quantum.

\subsubsection{Multiple Types of Data}

The internet has offer people a data-sharing platform where people could share various data on the internet intentionally or unintentionally every day; during which process, the internet not only recorded people's every hobbies but even the daily habits and routines. As thus, the data on the internet not only contains structured data such as information, symbols, and the unstructured data such as different kinds of pictures, voices and information and so on. While various data types also influence the data mining subsequently.

\subsubsection{High Flowability of Data}

In early period of internet, the network transmission rate was limited, and most data was transmitted by computer. Now with the popularization of networks on computers and mobile terminals as well as the high enhancement of transmission and acquisition efficiency of data, more timely information could be shared. Data of many software updated in seconds and endowed the data timeliness.

\subsubsection{Value of Low Density}

Constant with an almost exponential growth of the data amount, useful or available information does not increase much which gives more difficulty for the processing of data mining. As a consequence, useful information may only account for a small proportion in large amount of data so that the value density of data reduces correspondingly.

\subsection{Definition of Marketing}

Marketing, as defined, refers to the enterprises discovering or mining the prospect consumers' and business's demands to promote, spread and sell products from product' overall construction and its own types. It is mainly focused on deeply mining the embedded value of the products, meeting the demands of prospect consumers and most business, thus to help consumers know the process of the goods and finally purchase. The marketing could be classified as three types below:

Marketing is planning and carrying out the process about the products, services, ideas, pricing, promotion, and distribution. ( AMA,1985) [3]

Activity marketing is a series of scientific processes through a sequence of marketing research, planning and communicating in accordance with the demands of organizers which is based on activities.

Networks marketing means a series of trading in later period of all other media promotion including the media communication by internet.

\subsection{Big Data to the Promotion of Marketing}

With the progress of marketing economy, marketing has gradually become an important part of enterprises' core competitiveness and definitely plays a significant role in both enterprises and the whole society. The marketing's impact on enterprises has been detailed in Li Chenxi's published paper, pointed out that marketing could boost solving the contradiction between producing and 
consuming and promote rational use of social resources from social aspect; while from the enterprises' angle, marketing could add product value, promote rational use of enterprise resources, reduce the unmarketable products and finally achieve the win-win between enterprises and consumers. Therefore, enterprise marketing need formulate marketing positioning strategy, discover the potential demand of market, establish the brand loyalty and assure the market segmentation target. [6] With the arriving of big data era, consumer's needs tend to be unique, shopping channels become diversified and the initiative are gained unprecedentedly during the shopping process of consumers. Under this background, traditional marketing strategy based on experience instinct could not meet the needs of enterprise development. According to the demands of society on controllability and accuracy in each process of marketing management, the combination of big data and marketing management has become an inevitable tendency for the development of enterprises. In Zhenxing Yuan and Xixi Zheng's article, it stated that the improvement of marketing strategy by big data can be concluded as below. On the basis of the present literature review, this paper considered that big data's influences on marketing behaviors in following aspects.

\subsubsection{Improving the Accuracy of Marketing}

Big data helps build the network database and gather information about consumers in method of finding out potential customs first, then collect their demands and making customized strategies. Meanwhile, improving products based on consumers' consumption behaviors and accordingly promoted attracting the consumers' eyes. Enacting different promotion strategies to target and orient the enterprise products when facing consumers with different consumption capabilities.

Customs could be classified according to the characteristics including region, industry and gender and so on by mass data. In the meantime, in accordance with concluding the consumption behaviors of customs and potential customs, it could find out the sale circle variation during a specific period and when the demands of the products would increase obviously in a specific time. Finally, when summarizing the variation of products sales, it could understand customs thoroughly and classify into long-term customers and potential customers so that enterprises could explore and dig potential customer groups effectively and expand the market share as well as improve market competitiveness.

\subsubsection{Setting up A New Marketing Model}

Big data facilitates summarizing the shopping behavior habits and characteristics and finding out the correlation and consumption combination of consumers' preference of goods by mining and collecting present data; for instance, Wal-Mart found out the sale relations between beers and diapers by combination the both to increase their sales. After discovering the relations between the goods, it boosts the enterprises to formulate better sale strategies, innovate marketers improving products' marketing mode and finally set up a new cross consumption pattern based on the relations and purchasing habits.

\subsubsection{Predict Customer Behavior Accurately}

(1) Predict on basis of relations between products.

In big data era, enterprises could predict customers' consumption habits according to goods browse record, consulting records, personal preferences and purchasing records of customers and potential customers. Besides, in accordance with the correlation of products, it could accelerate enterprises in promotion purposefully so as to better keep potential consumers

(2) Make predictions based on relationships between products and external environment.

External environment also has impacts on goods sales except for the mutual influence between goods; for example, the university dormitory supplies sales would obviously rise at the beginning of term each year, additionally, sellers in barber shops or gyms around school would hire professional personnel for promotion. In America, some companies found in data that the sales of strawberry cookies would increase significantly in someplace before storm and even lead a shortage of supply; therefore, when at such time, related enterprises would increase the supply of this goods to meet customers' needs and improve the enterprise influence.

(3) Make predictions based on consumers' purchasing ability. 
By big data, enterprises could predict the consumers' choice for potential goods such as different specifications of same goods on the basis of consumers' purchasing patterns and the consumption quantity during a fixed period. Once IPhone has different storage ranging from 8GB to 256GB. While now the Apple Inc. has abandoned 8GB and 32GB, and IPhone sales rises gradually year by year. Which thanked to Apple Inc. who has made risk analysis according to customer behaviors and predicted strictly for the consequences of each decision before making determination of abandoning product specifications.

\section{Case Analysis}

In rapid development of internet technology, traditional business mode has been changed into internet business mode and now to mobile internet business. Surviving successfully for such a long time of companies such as Alibaba and Jd.com. has proved their adaptability to the times and their courage to innovate in this changing era. This paper would take Alibaba as an example to further demonstrate the contribution of big data to enterprise marketing innovation.

Mayun, Alibaba's CEO, has early put forward that nowadays the era has developed gradually from the internet to data times, therefore the target of Alibaba is to build infrastructure of Chinese business in big data era. Henceforth, Alibaba emphasizes on every detailed data produced and collected and analyzes the information including browsing history, purchasing records and brands and so on. During "Double 11" shopping carnival in 2013, Alibaba pushed out "Thousands of faces" based on big data, which means dividing different consumers into specific venues based on analyzing and using the shopping behaviors such as browsing, cart adding, collecting and even the records on shopping red envelopes snatching of consumers during the activity preheating periods. While in 2016's "Double 11", the function of "Thousands of faces" has achieved further development. Every Ecommerce could implement the function of "Thousands of faces" within their own business under condition of big data sharing of Alibaba. In this situation, E-commerce could display their products intelligently on main interface by analyzing big data of consumers so as to improve customers' shopping efficiency and meanwhile, Alibaba and other E-commerce could also gain huge profits.

\section{The Challenge of Combination of Big Data and Marketing}

Although the combination of big data and marketing is an inevitable trend for enterprise marketing and it could also bring great benefits for enterprises, it is undeniable that the development of big data in field of marketing are faced with many challenges whether from big data technology itself or the cultivation of professionals; additionally, most enterprises are in pioneering stage and some are holding a wait-and-see attitude toward this emerging technology, also it lacks relevant laws and regulations for protection at present. The challenges mainly contain as follow:

\subsection{Undesirable Information Affects Consumers}

Practical applications of big data cannot reach ideal conditions. Consumers would rise beauty fatigue and negative resistances to network marketing as well as lose trusts on advertising information provided by precision marketing owing to plenty of junk data information produced when the product oriented its position.

\subsection{The Ability of Marketers' Mastering Information Affects the Marketing Results}

Combination of big data's application and marketing need marketer's ability of deeper information processing. In China, professionals cultivation mainly based on the school and society; while the school's cultivation has disadvantages of low speed, strong theoretic and lack of practice and so on. The society's talented training is lack of systematic and scientific. The needs for professionals of big data require high comprehensive quality which combine big data with marketing effectively and flexibly. Therefore, traditional professionals' cultivation need improvement and the enterprises need input more cost for marketing personnel cultivation. 


\subsection{Negative Attitudes of Enterprises}

At present, big data is relatively new for enterprise marketers and the enterprise management level is still keeping a wait-and-see attitudes towards whether putting big data into marketing. Meanwhile, it's a big investment on cultivating the professionals and the input of necessary equipment which would suffer economic losses if failed receiving expected profits; in this circumstance, most enterprises chose to avoid the big risks of applying big data and continue the traditional marketing mode. They would try combination of big data and marketing only when the data mining and analyzing technology gets mature. As a result, it impeded the development of big data in China owing to enterprises' conservative attitudes to big data.

\subsection{Serious Fragmented Information Within the Enterprise}

In Chinese enterprise marketing management mode, most enterprises adopted team competition to improve sales; as a result, the information of consumers and clients were kept in different teams that marketers could not deeply comprehend the customers even though the information were collected and shared in all sale teams.

Besides, the enterprises could be considered as an integrated whole composed of multiple departments where the collected data is not well-rounded during the original data collecting process; as a consequence, it is difficult for original data to be deeply mined and applied which made the data hardly shared between departments.

\subsection{The Balance between Data Opening and Its Privacy Protection}

Under the background of big data, product marketing takes mass original data as a core. The enterprises analyze the data and achieve the combination of precise marketing and strategy of scientific consumption for consumers by rationally obtaining the data about personal information, consumption and browsing records. However. The laws and regulations about the data sharing is imperfect in China. It would be a big problem for the combination of the big data and other fields such as how to dig and apply the data under strict supervision, how to balance the data opening and privacy protection.

\section{The Suggestions on the Future Development of Big Data}

\subsection{Focus on Cultivating Marketing Talents of Big Data}

In era of big data, although data is the basis of success of enterprise marketing, the data mining technology and relevant professionals are essentially key factors for combination with enterprise marketing as well. With technology and talents, the enterprises could maximize the value of data resources and further insight into the customers' consumption behaviors to forecast the consumption trend so as to achieve greater benefits.

\subsection{Improving the Resources Sharing of Big Data}

It is obviously seen that data resource sharing could bring great benefits for enterprises from the case of Alibaba's integrated strategy "thousands of faces" to every E-commerce's "thousands of faces" after data sharing of consumption behaviors and browsing records and so on. The enterprise could find out the relations ignored before when it integrated itself as a whole and mined information of consumers and clients. While this relation is precisely the characteristics of big data, converting from causal relationship to correlation relationships, which could offer more opportunities for enterprises to discover and use the relations between data to achieve greater benefits

\subsection{Improve the Relevant Laws and Regulations About Big Data}

At present, data leakage has always been a focus of public attention and the PRISM in 2013 has also raised people's alarm on it. The information leakage of consumers would bring very bad influence on enterprises which not only make the enterprises lose the trust of consumers but lead to 
consumers' holding negative attitude toward network marketing. Besides, it would damage both of enterprise development and the combination development of big data and marketing if some criminals make use of leaked personal data to spread passive information. Therefore, a sound legal system and strict supervision of relevant departments on personal data protection would indirectly promote the domestic development of big data.

\section{Conclusion}

Marketing is considered as a significant process in product consumption. By the combination with big data technology, most problems that traditional marketing faced with could be solved. Meanwhile, marketers could grasp the market rules and improve the efficiency of enterprise marketing better by using big data to insight into consumers' consumption psychology and their habits of shopping behaviors. Although there are many problems and obstacles existing in the process of the combination of marketing and big data application, enterprises should actively face the difficulties and discover the broad prospects of big data marketing so as to make full use of it.

\section{References}

[1]. David Gelernter "Mirror Worlds: or the Day Software Puts the Universe in a Shoebox...How It Will Happen and What It Will Mean".

[2]. Liwung Jian, Xin Xu. Discussion on the essence of "big data" and its marketing connotations [J]. Nanjing Social Science, 2013(7):15-21.

[3]. AMA- American marketing association 1985.

[4]. https://baike.baidu.com/item/150434?Fr=Aladdin.

[5]. https://en.wikipedia.org/wiki/Marketing.

[6]. Yi Yin. Discussion on formulation procedures of marketing strategy and implementation strategy of enterprises [J]. Market Forum. 2011(1):75-77.

[7]. Chennai Li. Analysis on the marketing of small and medium-sized enterprises [J]. Research on Financial and Economic Issues. 2015(6):56-58.

[8]. Yuan hexing. Research on Marketing based on big data environment [J]. Modern Marketing. 2017 (12): 64- 64.

[9]. Jixi Zheng. Research on marketing reform in the era of big data [J]. China market, 2018 (2): 131132. 